\title{
Strategi Komunikasi Public Relations Aston Imperium Hotel dalam Mempertahankan Kearifan Lokal di Era 4.0
}

\author{
${ }^{1}$ Sefy Andhriany, ${ }^{2}$ Rahmawati Putri \\ Program Studi Ilmu Komunikasi, Fakultas Bisnis dan Ilmu Sosial \\ Universitas Amikom Purwokerto \\ Email: ${ }^{1}$ sefyandhriany09@gmail.com, ${ }^{2}$ rachma.rwp0601@gmail.com
}

\begin{abstract}
Abstrak
Melestarikan budaya lokal dengan mencerminkannya ke dalam setiap kegiatan organisasi atau perusahaan menjadi sebuah tantangan bagi Public Relations di era digital 4.0. Hal ini disebabkan adanya pergeseran budaya lokal yang digantikan dengan budaya asing yang masuk ke Indonesia. Berbagai macam strategi komunikasi dilakukan, salah satunya oleh Public Relations hotel Aston Imperium Purwokerto yang mempertahankan kekhasan budaya setempat di hotel tersebut. Penelitian ini bertujuan untuk menganalisis strategi komunikasi yang dilakukan oleh Public Relations hotel Aston Imperium dalam mempertahankan kearifan lokal di era 4.0. Penelitian ini menggunakan metode penelitian kualitatif dengan teknik pegumpulan data melalui wawancara mendalam, observasi, dan studi literatur yang terkait topik penelitian. Hasil penelitian ini menunjukkan bahwa strategi komunikasi Public Relations Hotel Aston Imperium dilaksanakan secara internal dan eksternal. Secara internal, Public Relations di antaranya memasukkan unsur-unsur budaya lokal dalam bentuk sajian makanan khas daerah Banyumas, interior hotel, kamar dengan menampilkan hiasan wayang dan motif batik Banyumas, serta pegawai yang menyisipkan bahasa Banyumas dalam menyapa tamu. Selain itu, Public Relations menyediakan counter pakaian dan hiasan batik di hotel. Secara eksternal, PR hotel Aston menjalin kerjasama dengan pemerintah daerah dan dinas pariwisata untuk mendukung upaya mempertahankan kearifan lokal.
\end{abstract}

Kata Kunci: Strategi Komunikasi; Public Relations; Kearifan Lokal

\begin{abstract}
Preserving local culture by reflecting it in every organization's activities becomes a challenge for Public Relations in the digital era 4.0. This is due to a shift in local culture which was replaced by foreign cultures that entered Indonesia. Various kinds of communication strategies are carried out, one of them is by the Public Relations of Aston Imperium Purwokerto hotel which maintains the local cultural specialties at the hotel. This study aims to analyze the communication strategy carried out by Aston Imperium Hotel Public Relations in maintaining local diversity in the 4.0 era. This study uses qualitative research methods with data collection techniques through in-depth interviews, observation, and related literature studies. The results of this study indicate that the Aston Imperium Hotel Public Relations communication strategy is implemented internally and
\end{abstract}


externally. Internally, local culture is included in the forms of food and beverage, Banyumas regional specialties, hotel interiors and rooms by displaying puppet decorations and Banyumas batik motifs, employees inserting Banyumas local language in greeting guests, providing clothing counters and batik decorations in the hotel. Externally, Aston hotel PR cooperates with the local government and tourism office to support maintaining local wisdom.

Keywords: Communication Strategy; Public Relations; Local wisdom.

\section{PENDAHULUAN}

Purwokerto merupakan sebuah kota yang dijuluki sebagai kota di jalur selatan Jawa Tengah. Namun, sebenarnya banyak julukan yang disandang oleh Kota Purwokerto ini seperti kota wisata, kota transit hingga kota pensiunan karena begitu banyak orang asli Purwokerto yang bekerja di kota lain, pensiun dan kembali untuk menetap di kota ini. Wilayah Kota Purwokerto sebenarnya tidak terlalu luas hanya 38,58 km2. (https://id.m.wikipedia.org/wiki/Purwokerto_(kota) sehingga perlu menumbuhkan konsep kota yang tepat.

Berkembangnya Kota Purwokerto sebagai kota yang menurut banyak orang merupakan kota yang nyaman dan asri serta memiliki banyak sekali tempat destinasi wisata turut membuat pemilik bisnis properti tertarik untuk membuat inovasi terbaru. Selain itu, kuliner/makanan khas yang ada di kota ini cukup menarik selera masyarakat lokal maupun pendatang. Makanan yang khas dari Purwokerto di antaranya mendoan, tahu brontak, kripik tempe, sroto/soto, gethuk goreng dan masih banyak lagi. Sebagai kota transit, Purwokerto menyediakan berbagai pilihan tempat penginapan mulai dari losmen, hotel kelas melati hingga hotel berbintang.

Di zaman modern ini, cukup banyak perusahaan, organisasi serta masyarakat yang sangat selektif dalam memilih pelayanan termasuk pelayanan dalam bidang jasa, salah satunya adalah jasa hotel. Maraknya bisnis jasa hotel di Purwokerto menyebabkan hotel-hotel ini makin berlomba-lomba untuk memberikan pelayanan yang prima bagi tamunya. Keberadaan Public Relations dituntut untuk dapat merumuskan berbagai macam strategi yang tepat untuk dapat menyasar targetnya. Salah satu hal yang sangat penting adalah kemampuan untuk dapat memelihara citra baik hotelnya.

Fungsi Public Relations menunjang manajemen mencapai tujuan-tujuan organisasi sebagai bagian yang terintegrasi dengan fungsi organisasi, baik organisasi bisnis maupun bisnis modern. Hal tersebut senada denngan yang diungkapkan oleh Harlow dalam Ruslan (2010) bahwa Public Relations merupakan fungsi manajemen yang khas, menjaga jalur bersama antara perusahaan dengan publiknya, yang terdiri dari aktivitas komunikasi, pengertian, penerimaan dan kerja sama.

Di era digitalisasi 4.0 di mana semuanya serba memanfaatkan kemajuan teknologi, Public Relations hotel harus membuat inovasi pembaharuan yang berbeda dengan hotel lain dengan memperhatikan value gap. Hal tersebut menjadi daya tarik tersendiri bagi masyarakat. Maulana (2015) menyatakan bahwa value gap merupakan celah tawaran yang masih terbuka luas dan mudah untuk diraih karena belum dimiliki oleh teman-temannya atau pesaing yang menggarap audiens 
yang sama. Di bawah ini ditampilkan tabel analisas value gap, di mana Value 2 dan Value 4 merupakan Value Gap.

I. Tabel 1. Analisa Value Gap (Maulana, 2015)

\begin{tabular}{|l|l|l|l|}
\hline \multicolumn{1}{|c|}{$\begin{array}{c}\text { Keinginan } \\
\text { Stakeholders }\end{array}$} & $\begin{array}{c}\text { Kompetensi } \\
\text { Teman/Pesaing }\end{array}$ & Kompetensi Diri & Action \\
\hline Need (value) 1 & $\begin{array}{l}\text { Sudah ditawarkan } \\
\text { orang lain secara } \\
\text { kuat }\end{array}$ & $\begin{array}{l}\text { Mampu } \\
\text { memberikan } \\
\text { tawaran yang } \\
\text { sama }\end{array}$ & Jangan Pilih \\
\hline Need (value) 2 & $\begin{array}{l}\text { Sudah ditawarkan } \\
\text { orang lain tetapi } \\
\text { masih lemah }\end{array}$ & $\begin{array}{l}\text { Mampu } \\
\text { memberikan } \\
\text { tawaran yang } \\
\text { lebih baik }\end{array}$ & Pilih \\
\hline Need (value) 3 & $\begin{array}{l}\text { Belum ditawarkan } \\
\text { orang lain }\end{array}$ & $\begin{array}{l}\text { Mampu } \\
\text { menawarkan value }\end{array}$ & Pilih \\
\hline Need (value) 4 & $\begin{array}{l}\text { Belum ditawarkan } \\
\text { orang lain }\end{array}$ & $\begin{array}{l}\text { Belum mampu } \\
\text { menawarkan } \\
\text { value tersebut }\end{array}$ & Tunda \\
\hline
\end{tabular}

Hotel Aston Imperium Purwokerto yang tergabung dalam jajaran manajemen Archipelago International Hotel, Resort and Residence merupakan sebuah hotel bisnis dan konvensi berbintang empat yang terletak di jantung kota Purwokerto. Hotel ini memiliki jajaran staf yang ramah dan sangat profesional disertai dengan keunggulan semua sistem bisnis dan hiburan terbaru, baik di kamar dan di seluruh bagian hotel. Hotel Aston memiliki 146 kamar yang luas dan suite yang canggih, empat ruang pertemuan dan ballroom yang dapat menampung hingga 1.000 tamu. Selain itu, Hotel Aston Imperium dilengkapi dengan kedai kopi, lounge lobi, kolam renang, ruang olahraga lengkap dan layanan spa untuk memastikan pengunjungnya yang menginap. (Sumber dokumen milik Aston Imperium Purwokerto.)

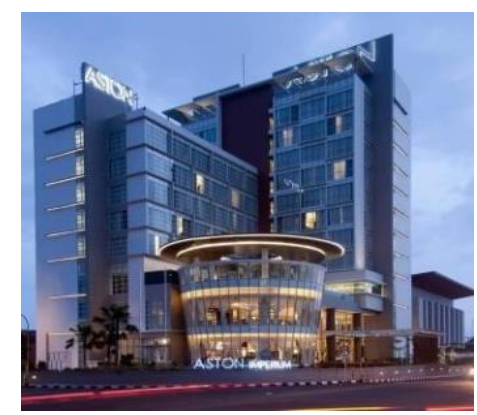

Gambar 1. Hotel Aston Imperium Purwokerto

Hotel Aston bertaraf internasional. Namun, hotel ini menekankan konsep kearifan lokal dalam setiap kegiatannya, baik secara eksternal maupun internal. Konsep tersebut didasarkan pada usaha pelestarian kekayaan budaya lokal Purwokerto, Banyumas dan sekitarnya agar tidak pudar. Berdasarkan uraian di 
atas, penulis tertarik menganalisis bagaimana strategi komunikasi Public Relations

Hotel Aston Imperium dalam mempertahankan kearifan lokal di Era 4.0?

\section{TINJAUAN PUSTAKA}

\section{Strategi Komunikasi Public Relations}

Public Relations merupakan proses interaksi untuk menumbuhkan opini dan persepsi publik sebagai input yang menguntungkan bagi perusahaan maupun publik dan menanamkan pengertian, menumbuhkan motivasi, dan partisipasi publik. Proses tersebut bertujuan menanamkan keinginan baik, kepercayaan, pengertian dan citra yang baik dari publiknya. Menurut Frank Jefkins dalam Syarifuddin (2016), Public Relations adalah sesuatu yang merangkum keseluruhan komunikasi yang terencana, baik ke dalam maupun ke luar, antara suatu organisasi dengan khalayaknya dalam rangka mencapai tujuan-tujuan yang spesifik berlandaskan pada saling pengertian.

Menurut Cutlip dan Center dalam Effendy (2009:116) PR adalah fungsi manajemen yang menilai sikap publik, mengidentifikasi kebijaksanaan dan tata cara seseorang atau organisasi demi kepentingan publik, serta merencanakan dan melakukan suatu program kegiatan untuk meraih pengertian dan dukungan publik. Sitepu (2011) menjelaskan Public Relations (PR) dalam makna yang sederhana adalah tatap muka (hubungan) antara kelompok-kelompok dalam suatu tatanan masyarakat.

Pada intinya Public Relations senantiasa berkenaan dengan kegiatan penciptaan pemahaman melalui informasi dan membagi pengetahuan. Melalui kegiatan tersebut diharapkan akan muncul suatu dampak perubahan yang positif. Jefkins menyatakan lebih lanjut ruang lingkup tujuan Public Relations adalah:

- Untuk mengubah citra umum di mata masyarakat terkait kegiatan-kegiatan baru yang dilakukan organisasi.

- Untuk menyebarkan cerita sukses organisasi kepada masyarakat dalam rangka mendapatkan pengakuan.

- Untuk meningkatkan bobot kualitas calon pegawai.

- Untuk memperbaiki hubungan antara organisasi dengan khalayak jika terjadi peristiwa yang mengakibatkan kecaman atau salah paham.

- Untuk mendidik para pengguna atau konsumen supaya lebih efektif dan mengerti ketika memanfaatkan produk organisasi.

- Untuk mendukung keterlibatan organisasi sebagai sponsor dari penyelenggaran suatu acara.

- Untuk memperkenalkan perusahaan kepada masyarakat luas, serta membuka pasar ekspor baru.

- Untuk mempersiapkan penerbitan saham tambahan atau karena adanya organisasi yang go public.

- Untuk meyakinkan khalayak bahwa organisasi mampu bertahan atau bangkit setelah krisis. 
- Untuk meningkatkan kemampuan dan ketahanan organisasi dalam rangka menghadapi risiko pengambilalihan.

- Untuk menciptakan identitas organisasi yang baru.

- Untuk menyebarluaskan informasi mengenai aktivitas dan partisipasi para pimpinan organisasi dalam kehidupan sosial sehari-hari.

- Untuk memastikan para politisi benar-benar memahami kegiatan atau produk yang positif supaya organisasi yang bersangkutan terhindar dari peraturan, undang-undang dan kebijakan yang merugikan.

- Untuk menyebarkan kegiatan-kegiatan riset yang telah dilakukan.

Pemahaman masyarakat terhadap profesi humas/Public Relations masih belum sepenuhnya benar. Persepsi masyarakat tentang humas masih berkisar pada masalah pekerjaan yang berkaitan dengan bagaimana menjalin hubungan dengan orang lain yang harus dilakukan oleh suatu lembaga.

\section{Pengertian Kearifan Lokal}

Kearifan lokal merupakan bagian dari budaya suatu masyarakat yang tidak dapat dipisahkan dari bahasa masyarakat itu sendiri. Biasanya kearifan local diwariskan secara turun-temurun dari suatu generasi ke generasi. Nilai-nilai tradisional yang melekat disetiap daerah itu sendiri, kearifan lokal sebagai suatu pengetahuan yang ditemukan oleh masyarakat lokal tertentu melalui kumpulan pengalaman dalam mencoba dan di integrasikan dengan pemahaman terhadap budaya dan keadaan alam suatu tempat.

Menurut Gobyah dalam Sartini (2004) bahwa kearifan lokal (local genius) adalah kebenaran yang telah mentradisi atau ajeg dalam suatu daerah. Sedangkan, menurut Sibarani (2012) kearifan lokal adalah kebijaksanaan atau pengetahuan asli suatu masyarakat yang berasal dari nilai luhur tradisi budaya untuk mengatur tatanan kehidupan masyarakat. Kearifan lokal juga dapat didefinisikan sebagai nilai budaya lokal yang dapat dimanfaatkan untuk mengatur tatanan kehidupan masyarakat secara arif atau bijaksana.

Konsep makna kearifan lokal tersebut sebenarnya hendak meyakinkan masyarakat untuk pentingnya tetap melestarikan kearifan lokal yang telah ada dan di wariskan. Namun, jika ditelisik dalam era 4.0 generasi sekarang lebih memodernkan dirinya sendiri hingga menganggap kebudayaan adalah primitif dan tidak perlu digunakan kembali. Akibatnya kita lupa akan budaya dan norma yang telah dibentuk dalam sistem masyarakat sekitar, sehingga kearifan lokal yang telah ada tersebut perlahan menghilang dan ada perubahan makna dari kearifan lokal tersebut.

Di Indonesia sudah banyak sekali penggunaan arsitektur yang berbau modernisasi, hingga kearifan lokal yang ditanam oleh masyarakat kian meluntur. Sebagai contohnya saja dengan konsep rumah yang di usung secara minimalis bentuk dan menghadirkan konsep estetika yang terlalu melebihkan. Pemikiran praktis mengenai milimalis tersebut yang membuat kearifan lokal kian meluntur. Dalam kasus modernitas/kebarat-baratan di Indonesia dampak yang dibawanya sangat terasa di lingkungan perkotaan sehingga nilai-nilai tradisional di banyaknya daerah mulai jarang ditemukan dan pengaruh dari modernisasi ini juga sudah merambah di pedesaan. Beberapa bangunan sudah menggunakan konsep modern 
tanpa adanya nilai tradisional, akan tetapi ada juga yang tetap menggunakan konsep modern tanpa menghilangkan nilai-nilai tradisional daerah yang memang sudah ada sejak dahulu. (https://id.m.wikipedia.org/wiki/Kearifan_lokal).

\section{Teori Citra}

Menurut Jefkins (2007), definisi citra dalam konteks humas merupakan kesan maupun cara pandang bagaimana seseorang, perusahaan, maupun publik memandang atas kebijakan jasa maupun produk yang dihasilkan oleh suatu perusahaan. Setiap perusahaan akan membuat citra sebaik mungkin agar bisa di terima oleh publik. Citra yang didapat oleh perusahaan bisa bersumber dari sebanyak pengetahuan dan pengalaman tentang fakta yang diperoleh publik.

Menurut Jefkins dalam Ardianto \& Soemirat (2003), jenis-jenis citra ada 4 dapat dijelaskan sebagai berikut,yaitu:

a) The Mirror Image (cerminan citra), yaitu bagaimana dugaan (citra) manajemen terhadap publik eksternal dalam melihat perusahaannya. Teori ini sering kali tidak tepat karena hanya bagian dari ilusi, biasanya dugaan - dugaan tersebut didapat karena pendapat maupun pandangan seseorang melihat objek yang berisikan informasi yang tidak memadai.

b) The Current Image (citra masih hangat), yaitu citra yang terdapat pada publik eksternal, yang berdasarkan pengalaman atau menyangkut miskinnya informasi dan pemahaman publik ekternal. Citra ini bisa saja bertentangan dengan mirror image. Teori ini biasanya menyangkut tentang informasi yang diperoleh terlalu minimalis ataupun sedikit-banyaknya nformasi yang seseorang yakini dan mempercayainya.

c) The Wish Image (citra yang diinginkan), yaitu manajemen menginginkan pencapaian prestasi tertentu. Citra ini diaplikasikan untuk sesuatu yang baru sebelum publik eksternal memperoleh informasi secara lengkap. Teori citra ini biasanya ada karena sebuah perusahaan maupun organisasi menginginkan apresiasi mengenai peluncuran inovasi terbaru mengenai objek yang khalayak belum memiliki informasi tentang hal tersebut.

d) The Multiple Image (citra yang berlapis), yaitu sejumlah individu, kantor cabang atau perwakilan perusahaan lainnya dapat membentuk citra tertentu yang belum tentu sesuai dengan keseragaman citra seluruh organisasi atau perusahaan.

Menurut Soemirat dan Elvinaro Ardianto, ada empat pembentukan citra:

a) Persepsi merupakan proses mengidentifikasi dari penerimaan yang diterima oleh indera manusia. Proses pengamatan indera yang menciptakan pemaknaan dengan kata lain seseorang akan membentuk sebuah makna terhadap objek yang diamati berdasarkan cara pandangnya melihat dari sisi mana individu dalam menilai sesuatu, dan dari persepsi inilah citra dapat terbentuk.

b) Kognisi merupakan suatu keyakinan mengenai diri individu yang didapatkan dari pengetahuan dan pengalaman terhadap objek yang dianalisis, dipahami dan dipikirkan.

c) Sikap merupakan kecenderungan perilaku, berpikir dan berpresepsi dalam menghadapi suatu objek.

d) Motivasi merupakan menggerakan kesan dalam diri seseorang untuk mendorong keinginan melakukan kegiatan tertentu. 
MODEL PEMBENTUKAN CITRA

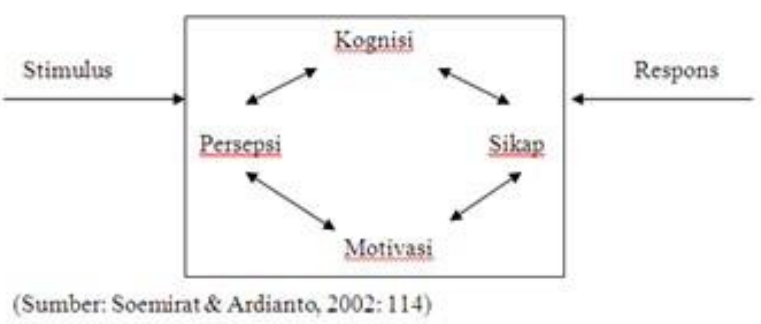

Faturohman, Rifin, dana Djohar dalam tulisannya berjudul Arsitektur Strategi Perusahaan Jasa Hospitality (Studi Kasus PT. Angkasa Pura Hotel) pada tahun 2019 menyatakan bahwa kompetensi inti perusahaan saat ini adalah sistem layanan reservasi dan layanan konsumen. Industri masa depan perusahaan adalah industri hospitaliti bandara dengan penguasaan kompetensi yang terkait dengan hospitality terdiri atas manajemen hospitaliti, manajemen layanan konsumen, desain interior hotel dan lounge dan desain menu makanan. Strategi penguasaan kompetensi inti melalui strategi aliansi dan mendirikan pusat pelatihan hospitality.

(https://journal.ipb.ac.id/index.php/jabm/article/viewFile/25666/17212)

Persamaan penelitian Faturohman dkk dengan penelitian ini adalah samasama menekankan pentingnya strategi komunikasi yang tepat pada industri hospitaliti di mana menekankan pada layanan konsumen dan ciri khas yang harus terlihat oleh tamu dalam hal desain interior hotel dan desain menu makanan. Sedangkan perbedaannya, penelitian Faturohman dkk menekankan pada hotel bandara yang berbeda dengan target tamu Hotel Aston Imperium Purwokerto.

Hasil penelitian Kurniawan dan Meytasari (2019) menunjukkan bahwa kesesuaian arsitektur hotel bintang dengan kearifan lokal yang ada di kawasan tersebut masih rendah yakni rata-rata 13,6\% ( masih dibawah 50\%). Sebagian besar hotel bintang dan bangunan vertikal belum mengadopsi jenis arsitektur yang sesuai dengan kawasan masing-masing. Hotal bintang dan bangunan vertikal masih menampilkan arsitektur modern dan kekinian sebagai arsitektur utama sedangkan arsitektur yang membawa nilai kearifan lokal hanya sebagai pelengkap dan pendukung.

Persamaan penelitian Kurniawan dengan penelitian ini adalah melibatkan arsitektur hotel yang berkearifan lokal dan menekankan pentingnya pencitraan ini pada setiap desainnya. Sedangkan perbedaannya, penelitian ini tidak menggunakan metode kuantitatif dan menekankan juga pada SOP hospitality yang tetap bernuansa kearifan lokal.

\section{METODE PENELITIAN}

Penelitian ini menggunakan metode kualitatif dengan pendekatan deskriptif. Dalam metode ini peneliti diharuskan untuk terjun langsung ke lapangan tanpa dibebani atau diarahkan oleh teori. karena dalam metode ini bebas mengamati objeknya, menjelajah, dan menemukan wawasan-wawasan baru sepanjang penelitian (Ardianto, 2016). Penelitian dilakukan di Hotel Aston Imperium Hotel Purwokerto yang beralamat di Jl. Overste Isdiman No. 33, Purwokerto 53114 Jawa Tengah, Indonesia.

Penulis melakukan pengumpulan data dengan melakukan observasi dan wawancara mendalam. Observasi digunakan untuk memperoleh data mengenai 
penerapan konsep kearifan lokal dalam era 4.0 di Hotel Aston Imperium Purwokerto. Sedangkan wawancara mendalam adalah teknik pengumpulan data atau informasi dengan cara bertatap muka langsung. Peneliti berkomunikasi langsung dengan informan, dalam hal ini (EV) selaku Marketing Public Relations Hotel Aston Imperium Purwokerto, (NE) selaku Director of Sales Hotel Aston Imperium Purwokerto dan PSN (Dosen Mata Kuliah Public Relations Universitas AMIKOM Purwokerto).

\section{HASIL DAN PEMBAHASAN}

Konsep yang diterapkan untuk melestarikan kearifan loal di Aston Imperium

Hotel Aston Imperium Purwokerto menawarkan konsep hotel internasional berbintang empat yang tetap mempertahankan dan melestarikan budaya setempat. Nilai-nilai tradisional tampak di hampir setiap sudut hotel yang langsung dapat dinikmati oleh tamu hotel. Hal tersebut tampak seperti pada seragam batik staf hotel terutama staf front office sehingga tamu langsung terpapar pada saat masuk hotel. Selain itu di lobby juga dipamerkan batik-batik khas Banyumas yang merupakan hasil kreasi masyarakat setempat di samping juga terdapat satu gerai khusus yang menjual kain batik, pakaian batik serta souvenir khas Banyumas. Setelah memasuki kamar hotel, tamu langsung disuguhi dengan interior kamar khas berbintang empat yang dikombinasi dengan lukisan wayang.

Konsep makna kearifan lokal tersebut sebenarnya hendak meyakinkan masyarakat untuk pentingnya tetap melestarikan kearifan lokal yang telah ada dan di wariskan. Sibarani (2012) menyatakan bahwa kearifan lokal merupakan kebijaksanaan atau pengetahuan asli suatu masyarakat yang berasal dari nilai luhur tradisi budaya untuk mengatur tatanan kehidupan masyarakat. Kearifan lokal juga dapat didefinisikan sebagai nilai budaya lokal yang dapat dimanfaatkan untuk mengatur tatanan kehidupan masyarakat secara arif atau bijaksana. Hotel Aston Imperium Purwokerto ini berdiri dan besar di tengah kebudayaan luhur Banyumas. Oleh karena itu, hotel ini terus berusaha mengusung dan mengangkat tema kearifan lokal Banyumas.

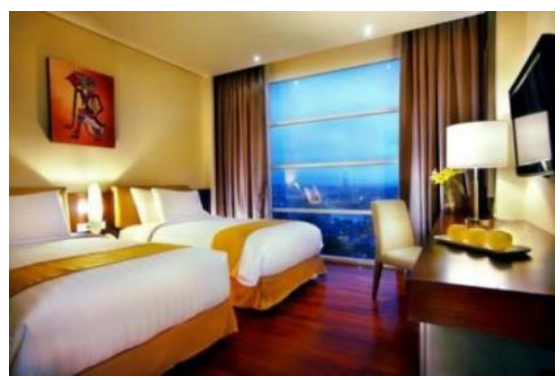

Gambar 2. Kamar Hotel Hotel Aston Imperium

Selain itu para tamu dimanjakan dengan layanan staf yang ramah dan profesional. Tentunya layanan hotel ini berdasarkan SOP atau Standard Operating Procedure. SOP yaitu prosedur operasi standar yang ada pada setiap perusahaan jasa, satu hal yang pasti setiap sistem manajemen yang memiliki kualitas baik selalu didasari oleh SOP. Standard Operating Procedure yang terdapat pada Aston Imperium Purwokerto ini salah satunya tentang hospitality pelayanan hotel. Bagian resepsonis contohnya memiliki tugas menyambut tamu hingga mengantarkan tamu sampai ke kamarnya. Tidak hanya itu, hospitality menjamin 
kenyamanan, keramahan dan profesionalitas hotel dalam memperlakukan tamunya. Tentunya dengan kombinasi atau balutan keramahan khas Banyumas yaitu dengan penggunaan bahasa jawa halus saat menyambut tamu serta gesture yang memperlihatkan ke andhap asor atau kesopanan setempat, seperti sedikit membungkuk ketika lewat di depan tamu dan berbicara dengan tamu.

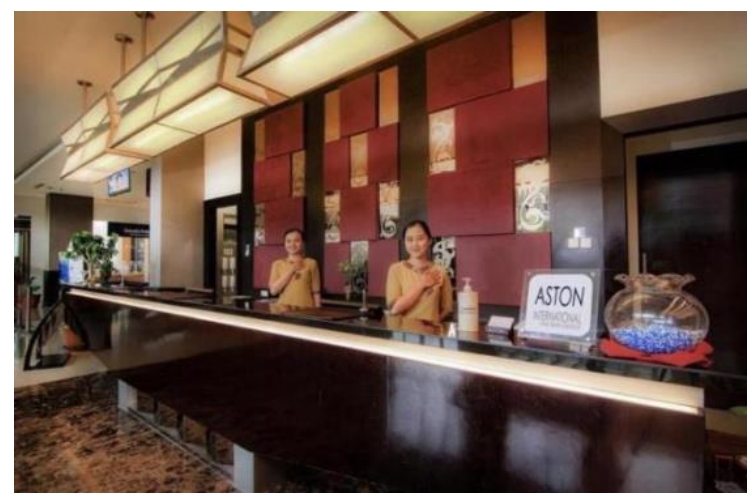

Gambar 3. Seragam batik dan salam khas Hotel Aston Imperium Hotel

Seperti terlihat pada gambar di atas, Hotel Aston Imperium Purwokerto juga ingin mencitrakan sebuah hotel internasional berbintang empat yang terus menjaga kearifan lokal dengan menjaga keramahtamahan, menghormati dan melayani tamu yang datang dengan senyum, salam dan sapa. Frank Jefkins menyatakan bahwa citra dalam konteks Public Relations merupakan kesan maupun cara pandang bagaimana seseorang, perusahaan, maupun publik memandang atas kebijakan jasa maupun produk yang dihasilkan oleh suatu perusahaan. Setiap perusahaan akan membuat citra sebaik mungkin agar bisa di terima oleh publik. Pada penelitian ini, Hotel Aston Imperium Purwokerto menggunakan The Wish Image (citra yang diinginkan) dalam setiap strategi komunikasi Public Relations nya.

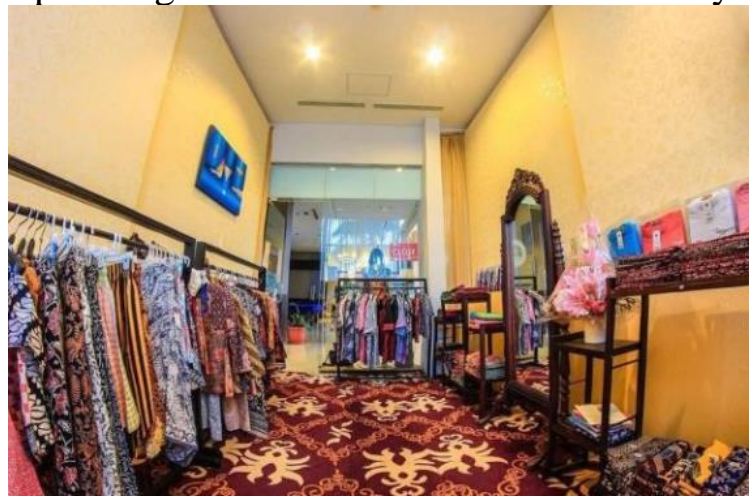

Gambar 4. Galeri Batik di Lobby Hotel Aston Imperium Purwokerto 


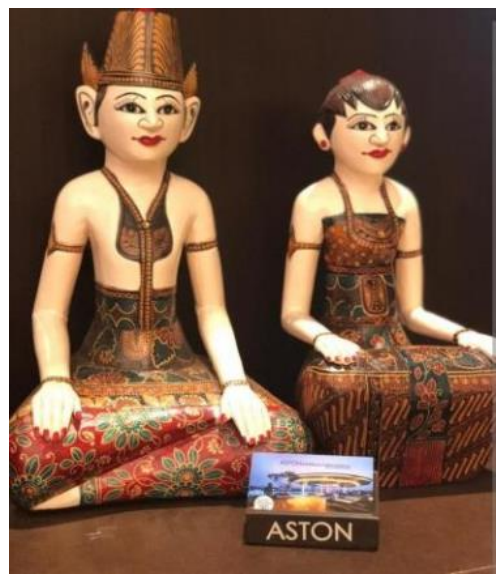

Gambar 5. Ornamen khas Banyumas yang terlihat di lobby hotel

Dengan segala kemodernan perkembangan di era 4.0 Hotel Aston Imperium Purwokerto ini tetap membangun kearifan budaya lokal Banyumasan yang tentunya membuat pengunjung tidak berpikir konsep hotel ini terlalu monoton. Konsep yang di usung hotel ini dalam kearifan lokalnya bisa di lihat juga dari makanan yang tersaji di restoran. Makanan khas dari Purwokerto dan Banyumas merupakan menu utama karena biasanya tamu mencari makanan khas dibanding makanan western.

Director Of Sales, NE menyatakan bahwa "Hotel Aston Imperium Purwokerto sengaja mengemas menu makanan yang berbeda dan bervariasi. Banyak tamu yang suka dengan menu yang disajikan, tapi seringkali tamu ingin menu yang memang khas Banyumas dan Purwokerto. Oleh karena itu kami mengadakan program Puas Makan Siang Sewarege di Aston Imperium Purwokerto. Uniknya, menu makan siang sewarege ini dikemas untuk memanjakan tamu dengan berbagai macam variasi makanan yang ngangenin."

EV menambahkan bahwa Marketing Public Relations program Puas Makan Siang Sewarege ini dirancang agar tamu tidak harus repot mampir di banyak tempat untuk menikmati kuliner khas Banyumas. Di sini berlaku kembali teori The Wish Image dalam program Puas Makan Siang Sewarege. Program yang dibuat oleh divisi Public Relations ini merupakan strategi manajemen yang menginginkan pencapaian prestasi tertentu. Citra ini diaplikasikan untuk sesuatu yang baru sebelum publik eksternal memperoleh informasi secara lengkap. Teori citra ini biasanya ada karena sebuah perusahaan maupun organisasi menginginkan apresiasi mengenai peluncuran inovasi terbaru tentang objek yang khalayak belum memiliki informasi tentang hal tersebut. 


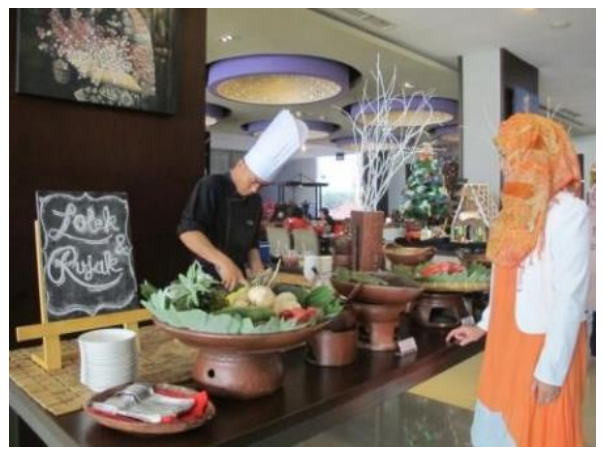

Gambar 6. Program Puas Makan Siang Sewarege Strategi Komunikasi Public Relations Hotel Aston Imperium Purwokerto

Strategi dalam sebuah perusahaan berhubungan diibartkan dengan usaha bertahan hidup dan berjuang melawan tekanan. Strategi yang digunakan oleh Hotel Aston Imperium Purwokerto sendiri dari segi marketing Public Relations menggunakan sistem segmentasi seperti wedding dan table manner jadi dari marketing sendiri sasarannya sudah sesuai dengan segmentasinya masing-masing marketing. Di era seperti sekarang ini yaitu era digitalisasi 4.0, Hotel Aston Imperium Purwokerto memiliki strategi baru yaitu lebih mengembangkan company profile untuk wedding-wedding apalagi untuk pemerintahan yang mungkin akan gencar untuk meeting atau acara lainnya.

Hotel Aston Imperium menggunakan media-media baru seperti bekerja sama dengan media untuk mencitrakan dirinya pada saat adanya event hotel aston yang memang mengharuskan media untuk meliput maka pihak hotel akan mengundang media. PSN mengatakan bahwa hotel sekaliber Aston yang termasuk dalam jajaran Archipelago Management tentunya harus mengikuti trend media baru, menggunakan strategi komunikasi yang digunakan oleh target pasar mereka. Diharapkan dengan penggunaan media yang tepat dan konten yang tepat dapat dengan efektif dan efisien tujuan bisnis perusahaanakan tercapai.

Tujuan pendirian dan sasaran perusahaan Hotel Aston Imperium ini memaksimalkan dirinya agar membuat pengunjungnya semakin tertarik untuk bekerja sama ataupun menginap disana. Hubungan baik dapat melahirkan berbagai keuntungan seperti halnya dukungan dan loyalitas tentunya hubungan baik antara suatu perusahaan/organisasi dengan publiknya merupakan suatu hal terpenting karena dari adanya hubungan baik akan mempengaruhi kesuksesan dan kegagalan suatu perusahaan/organisasi terlebih perusahaan jasa seperti hotel yang tentunya akan saling terus berhubungan dengan publiknya. Dalam hal ini juga berkaitan dengan seorang Public Relations karena perannya sangat dibutuhkan untuk membangun hubungan antara perusahaan dengan publiknya. 


\section{SIMPULAN}

Berdasarkan hasil penelitian dari Hotel Aston Imperium, di era yang sudah terbilang semua serba canggih dan modern ini pihak hotel tidak menutup kemungkinan untuk membawa kearifan lokal tetap terlestarikan. Strategi komunikasi Public Relations di Aston Imperium memaparkan unsur-unsur budaya yang dimasukkan kedalam desain mapun sistem operasional yang di gunakan untuk melayani tamu. Unsur-unsur budaya tersebut ditampilkan dalam bentuk sajian makanan khas daerah Banyumas, interior hotel dan kamar dengan menampilkan hiasan wayang dan motif batik Banyumas, pegawai menyisipkan bahasa Banyumas dalam menyapa tamu, menyediakan counter pakaian dan hiasan batik di hotel.

\section{Saran}

Bagi Hotel Aston Imperium Hotel yang berada di tengah-tengah kota, disarankan untuk tetap meningkatkan kearifan lokal yang ada. Selain itu, menyusun kembali strategi baru untuk segmentasi pasar yang lebih merakyat. Sementara itu, saran bagi penelitian berikutnya agar dapat memaksimalkan dan mendalami konsep strategi yang terdapat di perusahaan jasa layanan. Selain itu, perlu penelitian mengenai tanggapan konsumen terhadap pelayanan di Hotel Aston Imperium. Hasil penelitian tersebut akan bermanfaat untuk mengetahui strategi perusahaan dalam konsep bisnis perusahaan di industri yang baru.

\section{DAFTAR PUSTAKA}

Ardianto, Soleh Soemirat. 2002. Dasar-dasar Public Relations. Cetakan Pertama. Bandung: PT. Remaja Rosdakarya.

Ardianto, Elvinaro. 2016. Metode Penelitian untuk Public Relations Kuantitatif dan Kualitatif. Simbiosa Rekatama Media: Bandung.

Effendy, Onong Uchjana. 2009. Human Relations \& Public Relations. Bandung: Mandar Maju.

Kurnia Eddy, dkk. 2019. Komunikasi Korporat. Jakarta: Prenadamedia Group.

Maulana, Amalia E. Personal Branding.; Membangun Citra Diri yang Cemerlang. Jakarta: Etnomark Conculting.

Ruslan, Rosady. 2010. Manajemen Public Relations dan Media Komunikasi.

Jakarta: Rajawali Press.

Sitepu, Edy Sahputra dan Faulina. 2011. Profesional Public Relations. Medan:

USU Pers. 
Sartini. (2004). Menggali Kearifan Lokal Nusantara Sebagai Kajian Filsafati. Jurnal Filsafat.

Sibarani, Robert. 2012. KEARIFAN LOKAL: Hakikat, Peran, dan Metode Tradisi Lisan. Jakarta: Asosiasi Tradisi Lisan (ATL).

Syarifuddin, dkk. 2016. Public Relations. Yogyakarta: Penerbit Andi.

Jurnal

https://journal.ipb.ac.id/index.php/jabm/article/viewFile/25666/17212 (Diakses tanggal 9 Januari 2020).

https://id.m.wikipedia.org/wiki/Purwokerto_(kota) (Diakses tanggal 9 Januari 2020).

https://id.m.wikipedia.org/wiki/Kearifan_lokal (Di akses tanggal 5 Januari 2020). 